\title{
La educación física como espacio de transformación social y educativa: perspectivas desde los imaginarios sociales y la ciencia de la motricidad humana*
}

\author{
Physical Education as a space for social transformation and education: perspectives from \\ the social imaginaries and educational motricity
Educação Física como uma área de transformação socioeducacional: perspectivas a partir do imaginário social e da ciência da motricidade humana

\begin{abstract}
Alejandro Almonacid Fierro
Universidad Autónoma de Chile-Talca. Telf.: 56-71-342832. Correo electrónico: aalmonacidf@uautonoma.cl
\end{abstract}

\section{RESUMEN}

El artículo que a continuación se presenta aborda el fenómeno de la educación física como posibilidad de transformación humana, articulando los enfoques del imaginario social y la emergente perspectiva de la motricidad educativa. El despliegue didáctico de este sector de aprendizaje se ha caracterizado por el predominio de una lógica instrumental, tecnológica y positivista, que invisibiliza las complejas dimensiones de la persona humana, generando un reduccionismo ontológico que privilegia el desarrollo de un cuerpo funcional que permita alcanzar altos estándares de producción y, por consiguiente, de desarrollo económico, lo que conduce al debilitamiento de las nociones de sentido, significado y trascendencia tan propias del vivir humano en la relación yo, otro, sociedad. En este contexto, la motricidad educativa tiene la noble tarea de reencontrar al ser humano con su subjetividad, ponerla en relación con el otro, e iniciar los procesos de mudanza necesarios para alcanzar el preciado desarrollo humano y una sociedad mejor.

Palabras clave: educación física, transformación, imaginario social, motricidad educativa.

\begin{abstract}
This article below addresses the phenomenon of physical education as a possibility for human transformation, articulating the approaches of the social imaginary and the emerging perspective of the educational motricity, considering that the deployment of this educational learning sector has been characterized by the predominance of an instrumentalist logic, technological and positivist, which overlooks the complex dimensions of the human person, generating a ontological reductionism that favors the development of a functional body to achieve high production standards and, therefore, of economic development, by combining draft of the notions of sense, meaning and significance as own of the human life in the relationship of the I, the other, and the society. In this context, the educational motricity has the noble task of meeting the human being to his subjectivity, putting it in relation with the other, and starting the moving process necessary in order to achieve the precious human development and a better society.
\end{abstract}

Key words: physical education, transformation, social imaginary, educational motricity.

* Este artículo fue solicitado por la Revista Estudios Pedagógicos en diciembre del 2011 en el contexto del proyecto de Investigación FONDECYT (Fondo de Investigación Científica y Tecnológica) No 11110016 , titulado "Educación Física y su función de transformación de las desigualdades sociales: profesorado del área y documentación ministerial”. El artículo fue aceptado en junio de 2012. 


\begin{abstract}
RESUMO
Aborda-se o fenômeno da educação física como possibilidade de transformação humana, articulando enfoques do imaginário social e motricidade educativa e considerando que o desdobramento didático neste campo tem se caracterizado pelo predomínio de uma lógica instrumental, tecnológica e positivista, a qual invisibiliza complexas dimensões da pessoa humana, o que gera um reducionismo ontológico que privilegia o desenvolvimento de um corpo funcional capaz de alcançar elevados padrões de produção e, consequentemente, de desenvolvimento econômico, abstraindo daî as noções de sentido, significado e trancendência da vida humana na relação consigo, com o outro e com a sociedade. Neste contexto, a motricidade didática tem a nobre tarefa de favorecer o reencontro do ser humano com sua subjetividade, propondo a relação com o outro e início de processos de transformação necessários ao alcance do desenvolvimento humano e de uma sociedade melhor.
\end{abstract}

Palavras chave: educação física, transformação, imaginário social, motricidade educativa.

\title{
1. APROXIMACIONES AL CONCEPTO DE IMAGINARIO SOCIAL
}

En el entendido que los niño/as y jóvenes son partícipes fundamentales del fenómeno que emerge y se despliega en el aula de Educación Física, es que se espera reflexionar acerca del sentido y significado que ellos otorgan y reconocen en la construcción subjetiva de este subsector del currículo.

¿Por qué el concepto de imaginario? Esta pregunta se ha planteado anteriormente y quizás las palabras de Castoriadis nos ayuden a develar la interrogante "en primer lugar, ¿por qué imaginario? tendríamos que proporcionar quizás, en este festival, algunas palabras sobre esta noción. Imaginario porque la historia de la humanidad es la historia del imaginario humano y de sus obras" (Castoriadis, 2006: 93). De acuerdo al autor, en el transcurso de la historia humana la idea de imaginación -más que de imaginario-, fue expuesta primeramente en la obra de Aristóteles sólo de manera tangencial, para luego ser retomada por algunas escuelas platónicas como algo propio de la psique humana, y continúa de esta manera hasta las proximidades del siglo XIX, en consecuencia, no es sino hasta fines del 1800 y comienzos del 1900 que a través de los escritos de Kant, Fichte y Heidegger que la noción de imaginación se retoma con mayor fuerza.

El Grupo de Motricidad Humana y Mundos Simbólicos hace los siguientes planteamientos en relación al tema

"el concepto de imaginario se ha relacionado entre otros con la representación, la imagen, la realidad de lo simbólico considerándose como muy cercano a ella o incluso asumiéndose como sinónimos; pero con todo ello, ninguna de estas expresiones llena su total sentido toda vez que, en realidad el imaginario se va constituyendo como un interjuego entre cada una de estas, en un marco histórico y social de los sujetos" (Grupo Motricidad Humana y Mundos Simbólicos, 2005:50).

Consecuentemente con lo expuesto, los seres humanos logramos representar la realidad en imágenes, no obstante, estas imágenes se cargan de sentido a través de las múltiples relaciones que los seres humanos desarrollamos en la vida; de allí entonces comienza a emerger y a construirse el mundo de lo imaginario.

Los seres humanos desplegamos nuestra imaginación en el vivir y en el convivir con otros, toda vez que esta facultad -esencialmente humana- nos permite navegar por el universo externo-interno de nuestra existencia; es así como damos significado y sentido, por ejemplo, a la idea del bien y el mal, lo feo y lo hermoso, la vida y la muerte, realidad y fantasía. En el ejercicio imaginario entran en juego complejos procesos neurocebrales, que se traducen en impulsos eléctricos y luego en millones de posibilidades 
de sinapsis neuronales, que nos permiten representar la "realidad". Considerada de esta forma, la imaginación parece ser entonces un proceso en el proceso de construcción de realidades, en consecuencia, podemos hablar de multirealidades que se asoman-alejan en nuestra experiencia personal y social, de tal manera que lo que constituye en un sentido amplio la noción de la experiencia social -que recoge en buena parte lo que en filosofía simplemente se denomina como experiencia humana- (Salas, 2006; Baeza, 2003; Schütz, 1993), está teñida y tejida por la imaginación, facultad que le permite al hombre crear y recrear mundos, configurando en consecuencia la realidad como una construcción subjetiva e intersubjetiva del habitar humano.

Baeza (2003) nos entrega algunas aproximaciones a la idea de imaginación al plantear que es polifacética, pero sobre todo ambivalente, tan fugaz y autónoma (en términos relativos) como constante y dependiente, es decir, a la vez funcional y no funcional, metafórica y realista, simbolizante (con respecto a realidades complejas) y poética (con respecto a no realidades o meta-realidades), con y sin conexión con el entorno (natural, social, cultural, etc) del sujeto imaginante, efímera y duradera en el tiempo. De lo anterior, se rescatan los caracteres antagónicos, pero a las vez interdependientes, que conforman la imaginación, otorgándole una riqueza enorme de contenido, puesto que en su despliegue se observa una concepción no lineal o sumativa, sino más bien, una perspectiva holística, subjetiva, intuitiva, unitaria y múltiple a la vez. Lo aparentemente incompatible resulta ser absolutamente complementario; de ahí entonces que desde la misma imaginación que emergen los versos de la antipoesía surjan intrincados problemas matemáticos (refiriéndonos a la obra de Nicanor Parra), así también, la imaginación permitió que Colón emprendiera un viaje a lo desconocido y que Giordano Bruno muriera en la hoguera de la inquisición, sólo por imaginar una concepción distinta a la idea de centralidad del hombre impuesta por la iglesia católica en el confuso y oscuro siglo XVII.

La poderosa fuerza de la imaginación ha llevado a la humanidad a derroteros insospechados; ¿quien podía imaginar que un pueblo consumido después de la primera guerra mundial podría conducir una segunda guerra y adueñarse de la mitad de Europa a mediados del siglo XX? ¿quién podía imaginar que un pequeño país del Asia vencería al ejercito más poderoso del mundo? ¿quién podía imaginar que los escolares de la década de los 80 estaríamos sentados frente a una pantalla conectados al mundo y con miles de bits de información? El ser humano imaginó esto y mucho más, gracias a que según lo expresa Tello (2003: 15) "tiene una imaginación autónoma, tiene la capacidad de formular lo que no esta, de ver en cualquier cosa lo que no está allî” y seguramente esta capacidad y la puesta en juego de la experiencia humana, que se configura y reconfigura en el juego cruzado -y entrecruzado- de los dominios de la razón, emoción, historicidad, mismidad, dialogicidad y corporalidad de la persona humana, permitiendo el desarrollo del hombre y su vivir en sociedad.

En este sentido, la Educación Física ha plasmado a lo largo de su historia un imaginario que surge precisamente del hecho de conceptualizarla desde la experiencia, vale decir, cada vez que se entendió como preparación para la guerra, autocontrol, disciplina, cuidado y mantención del "cuerpo", rendimiento deportivo y más recientemente como instrumento de salud para la población, lo que emerge con nitidez es el sentido que la persona y la sociedad le ha otorgado a una actividad que pareciera no posee intencionalidad pedagógica, no favorece el desarrollo humano y se encuentra alejada de la discusión ideológica, para transformarse en una práctica de carácter instrumental, coercitiva y 
apolítica, lejos de la posibilidad de transformación social y humana propia de la acción educativa (Fernández, 2001; Toro, 2007; Moreno, 2011).

\section{VOCES PARA LOS IMAGINARIOS SOCIALES}

La vasta literatura en torno al concepto de imaginario permite reconocer la reflexión y la discusión que han realizado grandes pensadores frente al tema. Sin lugar a dudas, una de las figuras más connotadas es la de Cornelius Castoriadis, quien viene a poner en entredicho el desarrollo del pensamiento occidental, vale decir, viene a cuestionar la esencia misma del ser racional. Lo que cuestiona Castoriadis es aquella racionalidad tan propia de la civilización de occidente que se sustenta en el ser como determinación; podríamos argumentar desde el punto de vista epistemológico que esta mirada promueve aquella forma de conocer que privilegia lo verificable, lo objetivo, la relación causaefecto, lo numérico y cuantificable como única posibilidad del desarrollo científico, al pretender explicar los fenómenos.

Castoriadis plantea que resulta absolutamente natural llamar imaginario e imaginación a esta facultad de innovación radical de creación y formación. El lenguaje, las costumbres, las normas, la técnica, no pueden ser explicados por factores exteriores a las colectividades humanas, y ésta es precisamente la tesis que presenta a la filosofía de su época, de reconocer el imaginario colectivo, así como la imaginación del ser humano individual; lo que él visualiza es el poder de creación de nuevas formas para el lenguaje, la música, la pintura, lo que claramente se opone a una mirada determinista-racionalista del ser humano, llegando incluso a afirmar que la creación no tiene explicación racional, sólo es posible explicar la creación a través del imaginario y la relación individuo-mundo (Castoriadis, 2005; 2006; 2007; Tello, 2003).

Lo central aquí sería comprender que "ser" es una posibilidad y "no ser", es otra distinta, cuestión que se abordó a comienzos del siglo XX con los aportes de Heisenberg, Borr y Einstein, y con la aparición de la física cuántica a principios del 1900, lo que claramente genera un antes y un después en términos de la comprensión del mundo, puesto que

"Los planteamientos de la física cuántica invierten los de la mecánica y el mecanicismo clásico [...] La cuántica al no contar con objetos objetivos, sino con conexiones y relaciones tuvo que descartar las nociones deterministas y de causalidad lineal que permitían predecir los fenómenos, por las posibilidades de predecir probabilidades de varios resultados posibles" (Rozo, 2003: 31).

Podemos comprender, en consecuencia, que las nociones de fe por ejemplo, se configuran, no porque exista un dogma al respecto, como podría ser lo concerniente a los Santos en la iglesia católica, sino porque la devoción a -primero ciertos mártires de la iglesia y luego a destacados miembros del catolicismo- es un fenómeno que emerge a partir de la acción e interacción de determinados miembros de la "comunidad" católica, quienes comienzan a venerar, honrar, admirar, reverenciar y, en definitiva, a amar a una persona muerta, a través de diferentes prácticas, como podrían ser los diezmos, limosnas, sacrificios, rogativas, etc, que luego se van expandiendo a la mayoría de los miembros de la congregación, institucionalizándose como una práctica de "fe" con el paso del tiempo, de tal modo, que hoy no resulte extraño que en los meses de Enero y Marzo en el sur 
de Chile, se produzca todo un suceso en el pueblo de Yumbel, y una manifestación de la fe católica, que no es más que el significado que le otorgan las personas que asisten a esa peregrinación a un símbolo, en este caso la figura de un santo. Lo que vemos desplegado allí sería un imaginario social, circunscrito a una religión, una doctrina, una fe, constituyendo en definitiva una "red de significaciones", que transversaliza a una sociedad y una cultura en particular, impregnándola de ritos, mitos, leyendas, costumbres que caracterizan a la fe católica.

Por otro lado, Baeza expone que "los imaginarios sociales no son meras representaciones de algo real, sino elaboraciones "peri-racionales" [...] que participan en calidad de grandes supuestos en el proceso de significación, cuando este tipo de procesos es socializado, vale decir simbolizado" (Baeza, 2003: 81). El autor ejemplifica lo anterior con la noción de patria que poseen los habitantes de un territorio -en la mayor parte de las ocasiones este territorio es un acuerdo social que permite precisar e identificar determinados sectores-; no obstante, las concepciones de patria de personas que viven contiguas, como es el caso de judíos y palestinos en el medio oriente, es absolutamente diferente, puesto que las poblaciones de ambos territorios poseen una identidad nacional que tiene que ver con su historia, su lenguaje, su cultura, sus guerras, que evocan el concepto de nación a partir de los significados que le atribuyen al mismo en un proceso de socialización que parte en la familia, la escuela, el discurso social y en definitiva, en lo que viven, llegando a establecer un imaginario social "oficial" que se expresan en las concepciones de Dios, estado, dinero, tabú, pecado, hombre, mujer, partido, etc, que poseen las comunidades de manera colectiva y que van configurando su mundo, un mundo que es creado, vale decir, la sociedad es la que crea su propio mundo, otorgándole identidad, sentido, significación y un sistema propio de interpretación, que se va tejiendo, enhebrando, en-redando, urdiendo, en la sociedad y para la sociedad, conformando un "sí mismo" social. Quizás es aquí donde el aporte de los biólogos chilenos Maturana y Varela con su concepto de "autopoiesis" -característica esencial de lo vivo-, contribuye al desarrollo de la teoría social definiendo a la sociedad como sistema autopoiético de tercer orden (Maturana y Varela, 2004).

Por su parte, el sociólogo Juan Luis Pintos nos plantea que los imaginarios sociales serían precisamente aquellas representaciones colectivas que rigen los sistemas de identificación y de integración social y que hacen visible la invisibilidad social, entendiendo la invisibilidad social como aquello que subyace en las diferentes actuaciones humanas, por ejemplo, toda vez que un sistema social se impone como podría ser el caso del socialismo en la Europa oriental de la posguerra, nos encontramos con un determinado orden social, impuesto, dominante y hegemónico, que no hace más que visibilizar toda aquellas representaciones colectivas asociadas al capital, el poder, la justicia, la democracia, etc., configurando determinadas nociones de realidad, que de pronto chocan y se cruzan con el imaginario social de los pueblos sometidos (Pintos, 1993).

La Educación Física tradicional, por su parte, ha impuesto un sistema de valores asociados a la competencia, individualismo, exitismo y ciertas jerarquías, que se reflejan en aulas que excluyen y separan a los más "hábiles", de los menos "hábiles", con claras distinciones de género y con expresiones primarias de violencia que subsumen las cuestiones más de fondo como el significado de la acción deportivo-física, la promoción de la paz, la justicia, la inclusión, el ludismo y la creatividad (Almonacid y Matus, 2010; Jaramillo y Quilindo, 2006; López et al., 2003). 


\section{IMAGINARIO SOCIAL Y AULA DE EDUCACIÓN FÍSICA}

En primer término podemos señalar, citando a Trigo y Montoya (2007: 10) que "la expresión Educación Física nace en el iluminismo, con el predominio de la razón, Descartes define la Res Cogitas - Res Extensa, Alma y Cuerpo. Para estas dos entidades se diseñan dos vías de educación". En consecuencia, existiría una subordinación del trabajo físico al trabajo intelectual, lo que en términos pedagógicos se traduce en el predominio de ciertas facultades como las científicas y humanistas por sobre las expresiones corporales y artísticas.

La Educación Física contemporánea se caracteriza por su marcado acento médicomilitar, la que por una parte privilegia los aspectos asociados a la salud y al bienestar biológico de la persona, y por otro, aquella que prepara para la guerra, cuyo origen se encuentra en la Grecia pre-cristiana, y que está impregnada por la idea de disciplina del cuerpo, al que hay que gobernar, subyugar y en ocasiones hasta castigar. En estas concepciones el estudio y abordaje del ser humano se plantea desde una perspectiva más bien reduccionista, al focalizar su intervención en una dimensión de la persona, la referida al cuerpo o al físico, declarando explícitamente que el hombre y la mujer "tiene un cuerpo", el cual se transforma en un objeto que es analizado, observado e investigado desde el exterior, por consiguiente, este cuerpo se trabaja, entrena, alimenta, cansa, hidrata, recupera, en definitiva, vemos el planteamiento dualista característico del Cartesianismo del siglo XVII, tal como lo presenta Sergio y Toro (2005). Este enfoque filosófico constituyó la base teórica de lo que se entendió por racionalismo científico, el que sostenía, básicamente, que el ser humano era la suma de dos sustancias diferentes que se relacionaban, pero que no se combinaban, es decir, por un lado, existe la esencia corporal y, por otra, la esencia inteligible o razón. En este contexto, John Locke proponía años más tarde dos tipos de educación distintas, una orientada a la razón o mente y otra dirigida al cuerpo. Continuando con el planteamiento de Descartes, el neurobiólogo Antonio Damasio señala lo siguiente

"Y puesto que sabemos que Descartes imaginó que el pensar es una actividad muy separada del cuerpo, celebra la separación de la mente, la "cosa pensante" (res cogitans), del cuerpo no pensante, el que tiene extensión y partes mecánicas (res extensa)" (Damasio, 2006: 284).

Este es el pensamiento que ha predominado en el enfoque que se le ha dado a la Educación Física del siglo pasado. Lo que subyace en este paradigma es una noción de realidad, un pensamiento que considera al cuerpo como un objeto disociado de una mente que razona, esta concepción dualista es la misma a la que hacemos referencia cuando intentamos objetivar el conocimiento, tal y como lo expone Maturana (2005). En este contexto, más allá de una práctica fuertemente deportivizada que enfatiza y privilegia la dimensión biológica de la persona, lo que encontramos es una epistemología que asume el método científico, propio de la física newtoniana, como la manera válida para aproximarse al conocimiento, en consecuencia, la disciplina se despliega fundamentalmente desde un hacer "práctico", que se traduce en el desarrollo de ciertos estereotipos ligados a una técnica y/o movimientos específicos.

De lo expuesto precedentemente, podemos intentar acercarnos al aula del sub-sector Educación Física desde la noción de imaginario social, puesto que en los más de cien años en que se ha desarrollado la disciplina en el país, se ha instalado una comprensión 
sobre su sentido, estructura, finalidad, propósitos y proceso didáctico en las diferentes generaciones de estudiantes, constituyendo una representación colectiva de lo que la sociedad chilena entiende y significa como una actividad curricular que se despliega desde los primeros años de escolaridad, a través de continuos procesos de socialización que principian con imágenes que se cargan progresivamente de sentido y significado, vale decir el gimnasio, la pista atlética, la multicancha, el buzo, se entrecruzan en un juego recursivo de relaciones centrípetas y centrífugas a la vez, permitiendo la emergencia del imaginario escolar desde el aula de Educación Física, caracterizado por los siguiente elementos de acuerdo a las investigaciones desarrolladas por Hurtado y Jaramillo (2005), Jaramillo (2005), Toro (2007), De la Torre et al. (2007), Almonacid y Matus (2010), Moreno (2011).

- Un aula lineal y estructurada, puesto que la clase transcurre desde la perspectiva de la simplicidad, sumando elementos, superponiendo unos por sobre otros, desarrollándose de lo fácil a lo difícil con una idea de progresión, fragmentando el conocimiento en ciertos estereotipos dinámico-motrices que al final del curso se supone deben desplegarse con absoluta eficiencia en procura del rendimiento físico-deportivo.

- Un aula que reduce a la persona humana en la dualidad cuerpo-mente, toda vez la sesión se caracteriza por el trabajo con el cuerpo, en el marco de la concepción dualista de Platón, el que señala "la falta de actividad destruye la buena condición de todo ser humano, mientras que el movimiento y ejercicio físico metódico lo asegura y conserva" (Lopategui, 2002: 43). Posteriormente, es reivindicada por Rene Descartes tal como lo presenta Fritjof Capra: "René Descartes basó su visión de la naturaleza en la división fundamental entre dos ámbitos separados e independientes: el de la mente o sustancia pensante (res cogitans) y el de la materia o sustancia extensa (res extensa)" (Capra, 2002: 60) En consecuencia, el "cuerpo" es el instrumento al que se debe disciplinar en el marco de una Educación Física mecanicista. De lo anterior, se podría deducir que allí están presentes la ideología del control y la disciplina, propias de la Educación Física militarizada de principios del siglo XX, que aún se encuentra en el imaginario de algunos profesores y en gran parte de la sociedad.

- Un aula convertida en una sesión de entrenamiento, donde el énfasis se encuentra en el desarrollo de las cualidades físicas como la fuerza, resistencia, velocidad, abordando por tanto, sólo una dimensión de la persona humana e invisibilizando la totalidad y el carácter holístico del niño/a (Lopez et al., 2003).

- Una Educación Física tradicional, vale decir aquella clase fundada en una racionalidad positivista, en el marco de un modelo pedagógico de carácter academicista o tradicional, en consecuencia, contribuirá principalmente con la formación del carácter y la disciplina. En este contexto, la sesión de Educación Física tradicional alude a una instancia pasajera, efímera en algún caso, puesto que pareciera ser que los contenidos, en sus dimensiones conceptual, procedimental y actitudinal, no logran permear al estudiante, no logran que el niño/a le otorgue sentido a lo que hace, al final sólo se traduce en un hacer, que no tendría un sustento epistemológico.

- Un aula en la que predomina un modelo pedagógico autoritario asociado al mando directo, en el que se considera que el profesor es el poseedor del conocimiento y el alumno sólo debe seguir las órdenes con disciplina, sin posibilidad de convertirse en co-constructores de los saberes que se ponen en juego durante la clase, por otro lado, impide el desarrollo de la autonomía de la persona, principio esencial de todo proceso 
educativo. En este escenario, la sesión se aproxima más a una instancia mecanizada, y no a una posibilidad de crecimiento y despliegue de las potencialidades del niño/a. Como lo plantea Camacho (2004:27): "este modelo procura el fortalecimiento de cualidades innatas, recurriendo para ello a la repetición y a la incorporación de modelos predeterminados". En consecuencia, nos encontramos frente a una sesión de Educación Física que no es capaz de rescatar, extraer y hacer aflorar la riqueza y potencia del fenómeno educativo en el marco del desarrollo de la persona humana, caracterizado por principios de libertad, autonomía, respeto, empatía, los que, junto a otros, ennoblecen la acción pedagógica de la disciplina.

En definitiva, en este marco histórico-social, el aula de Educación Física se configura desde una lógica instrumental, con fuerte acento en la mejora de los índices de salud y condición física de la población, que tiene como objetivo implícito alcanzar mayores niveles de productividad, en el bien entendido que este sector de aprendizaje contribuirá a dotar a la persona de un "cuerpo" sano requerido para los desarrollos que la modernidad preconiza e instala en las sociedades que han suscrito a un modelo que tiende al individualismo, competitividad y exitismo.

\section{MOTRICIDAD HUMANA: INTERFACE PARA UNA EDUCACIÓN HUMANA, CONSCIENTE Y TRANSFORMADORA}

A fines de la década del 80, el filósofo Manuel Sergio presenta en Portugal su tesis doctoral denominada

"Un Corte Epistemológico de la Educación Física a la Motricidad Humana", en la que plantea que la "Ciencia de la Motricidad Humana assume um estatuto ontológico, porque pretende figurar no processo histórico, desde la Educacao Física, de raiz cartesiana e empirista, ate a $\mathrm{CMH}$, onde a fenomenología e hermenéutica predominan e, por tanto, onde se reconhece a primazia de intencional e do sentido sobre o meramente físico e reflexivo" (Sergio, 2003: 22).

El autor nos señala que el camino recorrido hasta este momento en el área de la Educación Física y el deporte ha sido un sendero marcadamente racionalista, dualista, instrumental y fuertemente anclado en el paradigma de la simplicidad, caracterizado por la disyunción, determinismo, orden, causalidad, linealidad y objetividad. Como contrapunto propone re-mirar el fenómeno desde el paradigma de la complejidad que da cuenta de una epistemología concebida a partir de la unidad del conocimiento, en una concepción de carácter holística y holográmica en el que el todo está presente en las partes y las partes presentes en el todo, que nos permite captar lo que es "tejido conjuntamente", puesto que "se trata de comprender un pensamiento que separa y que reduce mediante una forma de pensamiento que distingue y religa" (Morin, 2001: 45).

Para Manuel Sergio la motricidad humana "nao e o simple movimento, porque e praxis e, como tal, cultura (ou seja transformacao que a Home realiza, consciente e libremente, tanto em si mesmo como no Mundo o que o rodeia)...a motricidade e a capacidade para o movimento centrifugo da personalização" (2003: 148). Desde el punto de vista del autor, la motricidad humana supone lo siguiente:

- Una visión sistémica del hombre. Para poder precisar la concepción recurriremos a Rozo, quien señala que "la palabra sistema viene del griego synistanai y contiene 
nociones que significan reunir, juntar, colocar juntos" (Rozo, 2003: 51). En consecuencia, desde esta perspectiva, la mirada sistémica del ser humano hace referencia a una unidad, un todo integrado, un conjunto cuyas propiedades y características emergen del juego de relaciones y conexiones entre los elementos que lo configuran y entre el todo con el entorno en el cual se halla inscrito.

- La existencia de un ser no especializado y carenciado, abierto al mundo, a los otros y a la trascendencia. En esta idea encontramos la vulnerabilidad del ser humano, el que sólo alcanza niveles superiores de desarrollo a través de la interacción con otros seres humanos, el potencial biológico del hombre tiene limites que se superan en su condición de ser cultural y social.

- El hombre es un ser práxico. El ser humano tiene acceso a una experiencia de globalidad, es agente y factor de cultura, el hombre conoce y se conoce, transforma y se transforma, desde una concepción eminentemente compleja que hace emerger su multidimensionalidad.

Por otro lado, Kolyniak (2005: 32) en su propuesta de glosario inicial para la Ciencia de la Motricidad Humana la define como

"forma concreta de relación del ser humano con el mundo y con sus semejantes, relación ésta caracterizada por intencionalidad y significado [...] se refiere a sensaciones conscientes del ser humano en movimiento intencional y significativo en el espacio tiempo objetivo y representado, implicando percepción, memoria, proyección, afectividad, emoción, raciocinio. Se evidencia en diferentes formas de expresión -gestual, verbal, escénica, plástica"

Este autor propone una serie de conceptos asociados a esta nueva ciencia del hombre que viene a complementar lo ya expuesto por Manuel Sergio y otros investigadores, dando énfasis a la acción intencional que no separa, más bien reúne las diferentes dimensiones del ser humano, oponiéndose claramente al dualismo Cartesiano tan arraigado en la concepción de hombre que presenta la Educación Física tradicional, al plantear explícitamente la "educación de físicos". Por su parte Sergio y Toro (2005) enfatizan la idea de intencionalidad operante, tejida de emoción, cultura y proyectos personales y sociales.

En esta reflexión, se observa una mirada renovada que emerge con la sabiduría de Manuel Sergio, quien desde una perspectiva epistemológica levanta un nuevo paradigma denominado Motricidad Humana, para rescatar precisamente los aspectos humanos de trascendencia e intencionalidad que se encuentran cada vez que caminamos, jugamos y vivenciamos nuestra corporeidad. Es la energía expresada para la acción de superación, en todos los niveles: corpóreo, político y espiritual, social, etc.

Aparentemente, es la otra cara de la moneda, solo aparentemente, puesto que la Motricidad Humana sin Educación Física no tendría historia, vale decir, la MH tiene su génesis en lo que conocemos desde hace 300 años como Educación Física. La propia Educación Física sin la Motricidad Humana no tiene futuro, puesto que requiere con urgencia una transformación de carácter ontológico, epistemológico y didáctico. Ahora bien, por qué nos atrevemos a plantear que la Motricidad Humana no es el reverso de la moneda, porque si lo hiciéramos caeríamos en una concepción reduccionista y dualista del fenómeno, puesto que en lo esencial permite hacer girar la moneda y no sólo en un sentido sino en dos, en tres, en cuatro..., en todos los sentidos, generando una energía de tal magnitud que es capaz de hacer emerger una tormenta en un cálido día de verano.

Queremos comprender la MH, desde el paradigma de la complejidad -entendido este como lo que está tejido en conjunto (Morin, 2005), vale decir, lo que se une, enhebra, 
imbrica y relaciona de múltiples formas, permitiendo la máxima expresión de humanidad y sentido. Es lo que hace girar la moneda con cierta música, ritmo, acción, belleza, encanto, pasión..., revelando al hombre y la mujer que son capaces de amar y ser felices. En definitiva, la Motricidad Humana nos otorga la posibilidad de entender al hombre y a la mujer desde una mirada más humana, más plena, más sistémica, y en consecuencia, enriquece nuestra reflexión otorgando un carácter eminentemente pedagógico y de desarrollo humano al ámbito educativo-deportivo.

La red internacional de investigadores en Motricidad Humana señala que la ciencia de la Motricidad Humana nace, por tanto, de tres cortes epistemológicos. El primero es el de la disciplina, la Educación Física; el segundo es el del concepto clásico de ciencia; el tercero se refiere al concepto de conocimiento. En consecuencia, la Motricidad Humana viene a representar una nueva ciencia del hombre en la búsqueda permanente del desarrollo humano.

Desde la ciencia de la Motricidad Humana la Educación Física es vista como un espacio generoso en la construcción de sentidos y significados, para que hombres y mujeres puedan levantar proyectos de vida a partir de la relación, y en consecuencia, construir y compartir mundos posibles teniendo como telón de fondo la humanización de las actividades deportivas y recreativas que despliega el ser humano.

¿Cómo enfrentar los nuevos desafíos que se le presentan al sistema educativo desde el paradigma de la Motricidad Humana? Si acordamos que la institución educativa necesita cambiar, que los profesores están dispuestos al cambio, que la sociedad demanda un cambio educativo para sus ciudadanos, probablemente el problema radique en el hacia donde queremos ir y el sentido de la mudanza transformadora. En consecuencia, si pensamos hacia donde queremos ir como seres humanos y comenzamos a andar poco a poco, sin miedo a lo riesgos, sin miedo a las caídas, puede que el ser humano y, en consecuencia, la sociedad en su conjunto, emprenda un nuevo camino que se distinga por rescatar la esencia de ser humanos (Trigo, 2006).

\section{UN AULA EN PROCURA DEL DESARROLLO HUMANO}

La propuesta es una clase que integre y desenvuelva todas las dimensiones del niño/a, asociando este ejercicio pedagógico a la acción de la Motricidad Humana, comenzando por una re-conceptualización de la noción de corporeidad, toda vez que se asume que la noción corpórea es la percepción actualizada del estado de mi corporeidad, la integración del esquema, imagen, y conciencia corporal, en relación al contexto cultural y social que condiciona a los niño/as y jóvenes. Por su parte Zubiri (Cit. en Trigo, 1999: 79) entiende el concepto de la siguiente manera: "definimos la corporeidad como la vivenciación del hacer, sentir, pensar y querer, de manera que podemos identificar corporeidad con humanos". Esta conceptualización supera los supuestos filosóficos de la educación física, comprendiendo al ser humano desde una perspectiva que une, enhebra, teje y fundamentalmente complejiza al ser humano en la relación yo, otro, cosmos. Por otro lado, la concepción de aprendizaje se inscribe en una clase donde lo central sería la promoción de la persona humana, en el marco de una propuesta valórica que adquiera sentido para los y las niño/as que participan de ella, se aproxima a proyectar la sesión de Educación Física en el marco del desarrollo humano, rompiendo con la tradición más 
instrumentalista y técnica de la disciplina y, por consiguiente, centrada en la complejidad de la persona humana.

En relación a la experiencia emocional, ésta se considera central para generar una relacionalidad que configure una manera de aprender distinta, tal y como lo expresa un destacado neurobiólogo

"emociones bien dirigidas y bien desplegadas parecen erigir un sistema de soporte sin el cual el edificio de la razón no puede operar adecuadamente. Estos resultados y su interpretación cuestionaron la idea de descartar la emoción como si fuera un lujo, una molestia, o un mero vestigio evolutivo" (Damasio, 2000: 58).

En consecuencia, atender lo que sienten los niño/as en la clase de Educación Física resulta muy valioso, en el entendido que ésta actitud y acción pedagógica rompe con los esquemas tradicionales de la disciplina para acercarse a la propuesta del paradigma de la Motricidad Humana, que considera como eje rector el despliegue emocional, como lo expone Toro (Toro, 2004: 171) cuando desarrolla los supuestos de la Motricidad Humana: "un humano que transita de lo esencialmente biológico hacia lo cultural a partir de su sustrato emocional que le permite diferenciar y establecer lo que requiere y necesita en la satisfacción y trascendencia". Por tanto, podemos modificar la relacionalidad de la clase, cuando somos capaces de cambiar nuestra dinámica estructural interna a partir de nuestro sustrato emocional, el que permitiría re-configurar nuestro hacer, otorgándole sentido y significado a la acción pedagógica. Lo que podemos rescatar es la intención de conocer más profundamente a los niño/as con los cuales se genera el acto educativo, de escucharlos, de acogerlos, de legitimarlos, en tanto y cuanto son personas en desarrollo con un universo de posibilidades a su alrededor, a través del dialogo legitimador y fundamentalmente desde una acción que rompe la mirada del niño/as como alumno, para pasar a una concepción más compleja, holística y humana, vale decir, la persona en sus múltiples posibilidades de desarrollo. Lo anterior permite trascender la concepción disciplinar clásica de la Educación Física, para navegar por derroteros más integrales y de corte fenomenológico, como los que encontramos en los planteamientos de la Ciencia de la Motricidad Humana.

El aula de Educación Física es posible transformarla en un espacio para el desarrollo de la creatividad, que a su vez favorezca la motivación por parte de los niño/as. En este sentido la didáctica que despliega el profesor emerge desde el cariño y afecto por los estudiantes y a partir de allí configura una nueva orientación para la clase, lo que nos permite plantear una perspectiva renovada del fenómeno educativo. Esta nueva mirada la podemos conectar con la Motricidad Humana, en el entendido de una clase con sentido, multidireccional, integradora, motivadora y entretenida que de cuenta de un re-mirar la clase, que va complejizando y enriqueciendo el fenómeno, tal y como lo expone el Grupo de Motricidad Humana y Mundos Simbólicos

"Vista así, la Motricidad Humana debe ser síntesis del ser humano, en tanto dialéctica de la teoría y la práctica, de la imaginación - lo simbólico y la realidad, en tanto construcción imaginaria que se desliza por los caminos de la realización social. Precisamente, recogiendo estos planteamientos de la motricidad como síntesis, la educación física puede dar un viraje hacia una perspectiva fenomenológica y hermenéutica que supere la herencia cartesiana" (Grupo de Motricidad Humana y Mundos Simbólicos, 2005: 49). 


\section{A MODO DE CONCLUSIÓN: PROPUESTAS DESDE LA MOTRICIDAD EDUCATIVA PARA UNA TRANSFORMACIÓN SOCIAL}

- Como primer acercamiento, reconocer que somos seres emocionales y que nos desenvolvemos en el sentir, en el bien entendido que no habría acción sin emoción, puesto que la emoción hace emerger la acción en un bucle recursivo, cuestión ampliamente demostrada en las investigaciones de Antonio Damasio (2000), quien plantea una relación armónica y sistémica entre emoción, sentimiento y consciencia, toda vez que sus soportes neurales se encuentran conectados y se despliegan simultáneamente en la acción del vivir humano, generando más tarde lo que conocemos como aprendizaje y subsecuentemente cultura. En este sentido la motricidad educativa promueve un aula transida por emociones como la amistad, alegría, entusiasmo y confianza, de tal manera de generar una didáctica que promueva la educación en valores, la inclusión, la perspectiva de género y la diferencia, la multiculturalidad, en definitiva un aula en procura del desarrollo humano.

- En términos relacionales, el respeto, la tolerancia y la diversidad, son principios que el profesor debería hacer suyos para enfrentar los procesos educativo-formativos con alguna posibilidad de desarrollo real. En este sentido, la relación del profesor con el alumno en construcción permanente a partir de los afectos, producto de una coherencia y consistencia íntima en que se considera al estudiante como un legítimo otro, como un proyecto inacabado de unicidad y a quien se debe escuchar y atender en su individualidad, generando de esta manera una plataforma única de desarrollo humano.

- El profesor procurando centrar el proceso educativo en el aprendizaje de los alumnos, es decir, intentando cambiar el paradigma tradicional predominantemente -centrado en la enseñanza- por aquel que pone énfasis en el auténtico desarrollo humano de los alumnos, con la consiguiente generación de conocimientos a partir de la historia y vivencias del estudiante. Asumiendo el planteamiento de Maturana, "educar se constituye en el proceso en el cual el niño o el adulto convive con otro y al convivir con el otro se transforma espontáneamente de manera que su modo de vivir se hace progresivamente mas congruente con el del otro" (Maturana, 2005: 29). Seguidamente, la enseñanza basada en la exposición y explicación es superada por una enseñanza basada en la indagación y la co-construcción del conocimiento.

- En términos paradigmáticos, la propuesta es levantar un nuevo paradigma -quizás no tan nuevo, sino más bien el de siempre- que dé cuenta de una epistemología concebida a partir de la unidad del conocimiento, en una concepción de carácter holística y holográmica en el que el todo está presente en las partes y las partes presentes en el todo, generando una serie de relaciones de tan alta magnitud que solo es posible aproximarnos a ella a través del paradigma de la complejidad, que nos permite captar lo que esta "tejido conjuntamente" (Morin, 2001). Lo anterior nos permitiría circular desde un conocimiento simplista hacia un conocimiento complejo, en el cual no existe separación, sino más bien, el conocimiento se entiende como un todo que se teje, enhebra, imbrica y se relaciona desde la unidad a la totalidad y de la totalidad a la unidad

Transitar desde la clásica y tradicional Educación Física, hacia los supuestos ontológicos, epistemológicos y metodológicos propuestos por la Ciencia de la Motricidad Humana, representa todo un desafío para el aula del sub-sector puesto que el profesorado -primeramente- el sistema escolar en un segundo momento y la comunidad educativa toda, 
deben principiar un proceso de mudanza profundo, donde lo esencial es configurar una nueva carta de navegación que ponga el acento en la persona humana y sus complejas y ricas dimensiones en relación consigo mismo, con el otro y en definitiva con el mundo y los mundos que construye en el trasegar del día a día, en el bien entendido que es posible que los seres humanos, poniendo en juego la poderosa fuerza de la imaginación, podamos soñar y perseguir la utopía de que otro mundo es posible.

\section{REFERENCIAS BIBLIOGRÁFICAS}

Almonacid, A. y Matus, M. (2010). The emergence of imagination of student in school from the hall of physical education. Fiep Bulletin, vol. 80, 758-761.

Baeza, M. (2003). Imaginarios Sociales. Apuntes para la discusión teórica y metodológica. Concepción: Editorial Universidad de Concepción.

Camacho, H. (2004). Modelos pedagógicos en educación física. Revista Kinesis, Vol.39, 26-37.

Capra, F. (2002). Las conexiones ocultas. Barcelona: Anagrama

Castoriadis, C. (2005). Los dominios del hombre. Cuarta reimpresión. Barcelona: Gedisa.

Castoriadis, C. (2006). Figuras de lo pensable. Primera reimpresión. Buenos Aires: Fondo de Cultura Económica.

Castoriadis, C. (2007). La institución imaginaria de la Sociedad. Buenos Aires: Edigraf. S.A.

Damasio, A. (2000). Sentir lo que sucede, cuerpo y emoción en la fábrica de la conciencia. Santiago: Andrés Bello.

Damasio, A. (2006). El error de Descartes. Cuarta impresión. Barcelona: Crítica.

De la Torre, E. y Rivera, E. y Trigueros, C. (2007). Creencias y concepciones de la educación física en evolución: el caso de la formación del profesorado de educación física en la educación primaria. Revista Tándem. Didáctica de la Educación Física, vol.23, 50-56.

Grupo Motricidad Humana y Mundos Simbólicos (2005). Imaginarios de l@s jóvenes escolares ante la clase de Educación Física: un reclamo por su visibilidad. Armenia: Kinesis.

Fernandez, J (2001). La sociedad, la escuela y la educación física del futuro. En Devis, J. (Coord.) La educación Física, el deporte y la salud en el siglo XXI. Alicante: Editorial Marfil.

Hurtado, D. y Jaramillo, L. (2005). Jóvenes e imaginarios de la educación física. Popayán: Universidad del Cauca.

Jaramillo, L. y Col. (2005). La Educación Física: ¿Un problema de preparación o seducción?. Armenia: Kinesis.

Jaramillo, L. y Quilindo, V. (2006). Paisajes, contenidos y métodos: sentidos que configuran la Educación Física como un siempre lo mismo. Revista Pensamiento Educativo, vol.38, 154-171.

Kolniak, C. (2005). Propuesta de un glosario inicial para la ciencia de la motricidad humana. Popayán: Universidad del Cauca.

Lopategui, E. (2002). Historia de la educación física, primera parte. Revista de Ciencias del Deporte, Educación Física y Recreación, Kinesis, Vol.35, 33 - 44.

López, V. Monjas, R. Pérez, D. (2003). Buscando alternativas a la forma de entender y practicar la educación física escolar. Barcelona: INDE. 
Maturana, H. y Varela, F. (2004). De maquinas y seres vivos autopoiesis: la organización de lo vivo. Buenos Aires. Coedición de editorial Universitaria con editorial Lumen.

Maturana, H. (2005). La objetividad un argumento para obligar. Santiago: Lom.

Moreno, A, (2011). Percepciones del profesorado universitario en relación a la función de transformación social de la educación física como asignatura del curriculum escolar: el caso de Chile. Tesis Doctoral Inédita. Granada: Universidad de Granada.

Morin, E. (2001). Los siete saberes necesarios para la educación del futuro. Barcelona: Paidos.

Morin, E. (2005). Introducción al pensamiento complejo. Barcelona: Gedisa.

Pintos, J. (1993). Orden social e imaginarios sociales. Santiago de Compostela. Dirección electrónica: http://web.usc.es/jlpintos/articulos/ordensocial.htm

Rozo, G. (2003). Sistémica y Pensamiento Complejo. Bogota: Biogénesis.

Salas, R. (2006). Epistemología y pre-comprensión de la experiencia socio-histórica I. Una visión de conjunto. Santiago: Ediciones Universidad Católica Silva Henríquez.

Sergio, M. (2003). Um corte epistemologico da educacao fisica a motricidade humana. Segunda edición. Lisboa: Instituto Piaget.

Sergio, M. y Toro, S. (2005). La motricidad humana, un corte epistemológico de la educación física. Popayán: Universidad del Cauca.

Schütz, A. (1993). La construcción significativa del mundo social. Barcelona: Paidós

Tello, N. (2003). Cornelius Castoriadis y el imaginario radical. Madrid: Campo de Ideas.

Toro, S. (2007). Una aproximación epistemológica a la didáctica de la motricidad desde el discurso y práctica docente. Revista Estudios Pedagógicos, Vol. XXXIII, n.1, 29 - 43.

Toro, S. (2004). Francisco Varela y su aporte a la Motricidad Humana. En Educación Física intervención y conocimiento científico. Piracicaba: Unimep.

Trigo, E. y Montoya, H. (2007). Aportes de la motricidad humana a la educación física. Revista Motricidad y Persona, n.10, 9 - 43.

Trigo, E. (2006). Inteligencia creadora, ludismo y motricidad. Popayán: Universidad del Cauca.

Trigo, E. coord. (1999). Fundamentos de la motricidad humana. Madrid: Gymnos. 